\title{
Gas escape behavior from bursting bubbles
}

\author{
Ali A. Dasouqi and David W. Murphy () \\ Department of Mechanical Engineering, University of South Florida, Tampa, Florida 33620, USA
}

(Received 14 July 2020; published 12 November 2020)

\begin{abstract}
This paper is associated with a video winner of a 2019 American Physical Society's Division of Fluid Dynamics (DFD) Gallery of Fluid Motion Award for work presented at the DFD Gallery of Fluid Motion. The original video is available online at the Gallery of Fluid Motion, https://doi.org/10.1103/APS.DFD.2019.GFM.V0072.
\end{abstract}

DOI: 10.1103/PhysRevFluids.5.110502

The bursting of bubbles at an air-liquid interface is important in air-sea interactions, food science, and industrial processes. Whereas the film retraction and droplet formation processes of bubble bursting have been well studied, the escape of pressurized gas from inside the bubble is not well understood but could have implications for the transport of vapor, odors, and aerosolized microdroplets near the liquid surface [1,2]. Vortex ring formation from bursting bubbles was first reported in 1858 by William Rogers, the founder of the Massachusetts Institute of Technology [3]. Here we use high-speed smoke visualization and stereophotogrammetry to visualize and measure the gas jet flow and subsequent production of vortex rings released from small $(2 R=3.91 \mathrm{~mm})$ and large $(2 R=22.7 \mathrm{~mm})$ bubbles bursting at the air-water interface, where $2 R$ is the bubble equivalent diameter [4]. Figure 1 shows the bursting of the small bubble, which, by the Young-Laplace equation $\Delta P=\frac{4 \sigma}{R}$ has an interior pressure that is $145 \mathrm{~Pa}$ greater than the surrounding atmosphere. At $t=$ $0.4 \mathrm{~ms}$, the bubble cap film has been completely destroyed, retracting at a speed of $V_{\mathrm{fr}}=5.19 \mathrm{~m} / \mathrm{s}$ (corresponding to a film thickness of $h=5.3 \mu \mathrm{m}$ by the Taylor-Culick formula $V_{f r}=\sqrt{2 \sigma / \rho h}$, where $\sigma$ and $\rho$ are the water surface tension and density, respectively), and a smoke jet has emerged at a speed of $V_{\text {jet }}=2.56 \mathrm{~m} / \mathrm{s}$ and at a jet Reynolds number $\operatorname{Re}_{\text {jet }}=\frac{V_{\text {jet }} D_{\text {jet }}}{v}$ of 106 , where $D_{\text {jet }}$ is the jet frontal diameter and $v$ is the kinematic viscosity of air. The smoke jet rolls up into a primary vortex ring which travels $32 \mathrm{~mm}$ before stopping. A secondary vortex ring is formed from the upward impulse of the Worthington jet (e.g., $t=14.8 \mathrm{~ms}$ ). Figure 2 shows the bursting of the large bubble which has an interior pressure that is $25 \mathrm{~Pa}$ greater than that of the surrounding atmosphere. At $t=0.4 \mathrm{~ms}$, a 2.3 -mm-diameter hole has opened in the bubble film through which the smoke is being ejected. The film retraction speed for the large bubble is slower (e.g., $V_{\mathrm{fr}}=2.73 \mathrm{~m} / \mathrm{s}$ ), corresponding to a larger film thickness of $h=18.9 \mu \mathrm{m}$. The jet speed at $t=0.4 \mathrm{~ms}$ is $V_{\text {jet }}=4.07 \mathrm{~m} / \mathrm{s}$ (larger than that of the small bubble), corresponding to $\mathrm{Re}_{\text {jet }}=517$. The jet rolls up into a large, oblate primary vortex ring, and the continuing retraction of the film creates a series of Kelvin-Helmholtz vortexlike instabilities in the smoke beneath the primary vortex ring (e.g., $t=2.8-6.4 \mathrm{~ms})$. The primary vortex ring generated from the large bubble travels a much longer distance $(173 \mathrm{~mm})$ in comparison to that generated by the small bubble. In comparing the behavior of these gas jets as a function of bubble size, it is remarkable that the large, low-pressure bubble generates a higher-speed jet. In general,

Published by the American Physical Society under the terms of the Creative Commons Attribution 4.0 International license. Further distribution of this work must maintain attribution to the author(s) and the published article's title, journal citation, and DOI. 


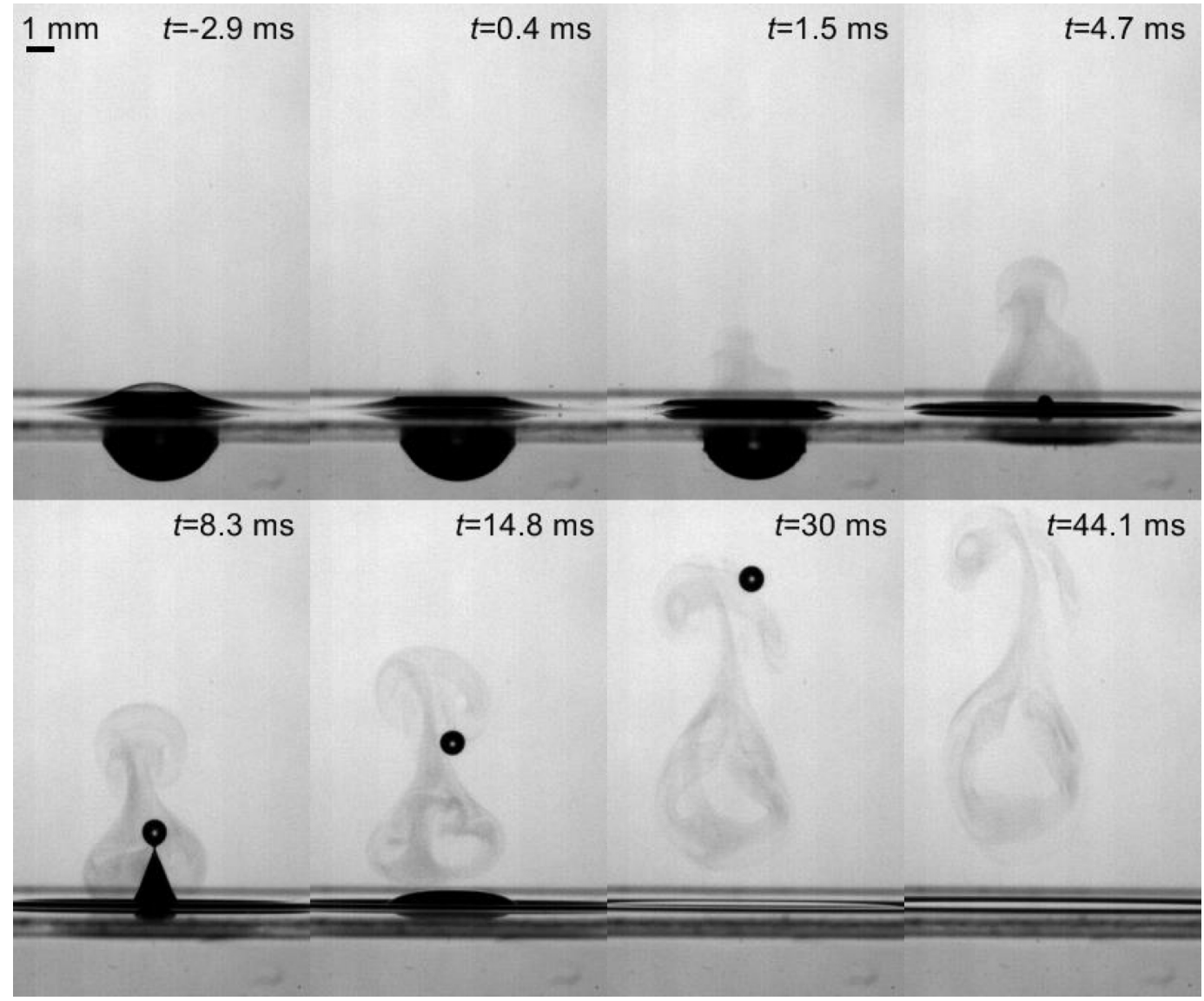

FIG. 1. Sample images from a time series showing the bursting of a $2 R=3.91 \mathrm{~mm}$ smoke-filled bubble floating on the water surface. The hole in the bubble cap forms at $t=0 \mathrm{~ms}$. [https://doi.org/10.1103/APS.DFD. 2019.GFM.V0072].

small bubbles have thin films which retract extremely rapidly, leading to relatively wide apertures through which low-speed gas jets are ejected. In contrast, large bubbles have thick films which retract more slowly, thus generating higher-speed jets released through relatively small openings. These jets and the resulting upward-traveling vortex rings generated by bubbles bursting at the air-sea interface may be important in transporting tiny marine aerosol droplets into the atmosphere.

The authors gratefully acknowledge Ali Alshamrani for laboratory assistance and Ferhat Karakas for assistance with analysis. Funding was provided by a National Academies Gulf Research Program Early Career Research Fellowship and a NSF CAREER award (Award No. 1846925) to D.W.M. 


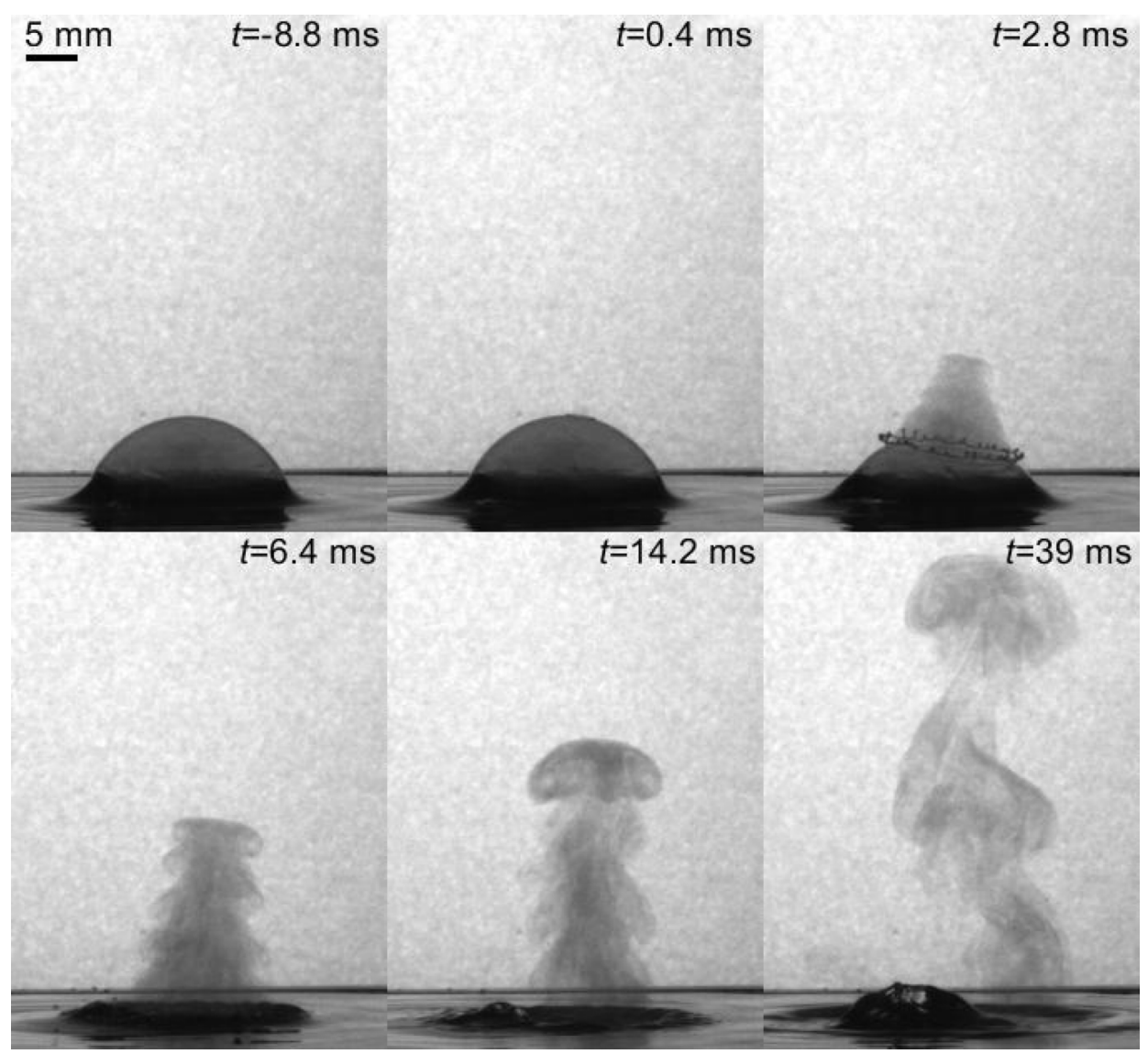

FIG. 2. Sample images from a time series showing the bursting of a $2 R=22.7 \mathrm{~mm}$ smoke-filled bubble floating on the water surface. The hole in the bubble cap forms at $t=0 \mathrm{~ms}$. [https://doi.org/10.1103/APS.DFD. 2019.GFM.V0072].

[1] J. A. Day, Production of droplets and salt nuclei by the bursting of air-bubble films, Q. J. R. Meteorol. Soc. 90, 72 (1964).

[2] M. J. Iacono and D. C. Blanchard, An investigation of vortex rings from bursting bubbles, Atmos. Res. 21, 139 (1987).

[3] W. B. Rogers, ART. XXXIII.-On the formation of rotating rings by air and liquids under certain conditions of discharge, Am. J. Sci. Arts 26, 246 (1858).

[4] M. A. Teixeira, S. Arscott, S. J. Cox, and P. I. Teixeira, What is the shape of an air bubble on a liquid surface? Langmuir 31, 13708 (2015). 